\title{
Simultaneous dehydration and infiltration with (2-hydroxyethyl)- methacrylate (HEMA) for lipid preservation in plant tissues
}

João Marcelo Santos de Oliveira ${ }^{1}$

Received: September 16, 2014 Accepted: December 1, 2014

\begin{abstract}
Although this study aims to develop an improved method for the preservation of reserve lipids in plant tissues for different uses in plant anatomy, it mostly aims to develop an improved method for the identification of lipid reserves where synthesis or storage occurs. The proposed procedures entail only the utilization of (2-hydroxyethyl)-methacrylate (HEMA) as a dehydration agent. One of the procedures is based on the gradual exchange of aqueous HEMA solutions with increasing concentrations. In another procedure, dehydration and infiltration are induced by the presence of silica gel around a modified microcentrifuge tube containing the aqueous HEMA solution with the plant tissues, thus allowing efficient lipid preservation. Both procedures resulted in simultaneous dehydration and infiltration of the endosperm and embryo of Ricinus communis, while eliminating the use of ethyl alcohol, thus providing better lipid preservation.
\end{abstract}

Keywords: embryo, endosperm, HEMA, lipids, plant anatomy, plant microtechnique

\section{Introduction}

Among the different histological procedures in plants, the most widely used procedure involves chemical fixation, dehydration, infiltration, and embedding of cells and tissues. The loss of proteins, carbohydrates, and lipids is common during these steps (Hayat 1970; O’Brien \& McCully 1981; Gerrits et al. 1990; Gerrits et al. 1992). Such losses lead to difficulties in structural, physiological, and functional interpretation. In this context, unfixed cellular elements are considered to be easily removed by solvents, although there have been reports in the literature of loss of neutral lipids and phospholipids even after fixation by osmium tetroxide (Korn \& Weisman 1966). Generally, it is common to employ fixation only by coagulating or non-additive agents or primary fixation for proteins during histological analysis of plants by light microscopy (Baker 1958; O’Brien \& McCully 1981), which results in significant cellular loss. Sugars and particularly lipids are lost during the processes of dehydration by ethanol or organic solvents as well as during infiltration and embedding (Baker 1958; Korn \& Weisman 1966; Hayat 1970).

Lipid preservation in plant cells can be achieved by chemical fixation, generally denominated secondary fixation, by using osmium tetroxide, which is an extremely toxic reagent (Bozzola \& Russel 1999). Some physical procedures such as cryosectioning, freeze substitution, and freeze drying also allow excellent preservation of cellular elements, including lipids, but are not widely applied in plant histology (Jensen 1962; Fritz \& Eschrich 1970; Laüchli et al. 1970; O'Brien \& McCully 1981; Dashek 2000; Reed 2008). Such procedures require special care and/or greater refining techniques in addition to specific equipments and/ or reagents, which are not commonly used in traditional procedures in plant histology.

Considering that diverse resins such as methacrylatebased resins, which are generally utilized for infiltration and embedding, are miscible in water in all proportions (Rosenberg et al. 1960; Hayat 1970; O'Brien \& McCully 1981), their use as a dehydration agent has been investigated (Rosenberg et al. 1960; Hayat 1970; Ashford et al. 1972; O’Brien \& McCully 1981; Meyer et al. 2009).

Dehydration with resins has the advantages of simplifying the dehydration process, eliminating the use of ethanol or organic solvents and reducing artifacts such as lipid loss (Rosenberg et al. 1960; Hayat 1970; O'Brien \& McCully 1981). However, the use of resins for dehydration has been insufficiently applied for plant tissues and has only been utilized with the objective of enzyme preservation and respective detection by histochemical methods and not with the objective of lipid preservation (Ashford et al. 1972).

Thus, the present study aims to develop alternative procedures for reserve lipid preservation in plant tissues using (2-hydroxyethyl)-methacrylate (HEMA) as both dehydrating and infiltrating agents.

\footnotetext{
${ }^{1}$ Laboratório de Botânica Estrutural, Departamento de Biologia, Universidade Federal de Santa Maria, Roraima, n 1000 , Cidade Universitária, 97105-900,
} Santa Maria, RS, Brazil, linneau@yahoo.com.br 


\section{Material and methods}

\section{Botanical material}

Ripe fruits of Ricinus communis L. (Euphorbiaceae) occurring in areas of the Universidade Federal de Santa Maria (UFSM) (Santa Maria, Rio Grande do Sul, Brazil) were collected.

\section{Fixation}

After collection, the fruits were dissected, the seeds were removed, and the endosperm and embryo were separated. The entire dissection process was performed on a Petri dish containing $0.1 \mathrm{M}$ sodium phosphate buffer ( $\mathrm{pH}$ 7.2). The embryos were transversally sectioned in the Petri dish in slices of approximately $1 \mathrm{~mm}$ thickness. After dissection, the embryo slices were placed in microcentrifuge tubes containing the fixative solution composed of 3\% glutaraldehyde in $0.1 \mathrm{M}$ sodium phosphate buffer of pH 7.2 (Gabriel 1982) and then exposed to a vacuum for $24 \mathrm{~h}$. After fixation, the material was washed in the same buffer, following two washings with distilled water.

\section{Preparation of HEMA}

A Leica HistoResin ${ }^{\text {tw }}$ was prepared with HEMA monomers, activator was made of benzoyl peroxide, and hardening agent was made of barbituric acid. The resin solution was prepared following the manufacturer guidelines for preparing HEMA infiltration solution (dilution of $0.5 \mathrm{~g}$ benzoyl peroxide in $100 \mathrm{ml}$ basic resin).

\section{Dehydration and infiltration}

The samples of plant tissue were dehydrated and embedded using the three different procedures described below. Samples from the same embryo were separated into three groups. Thus, part of the samples was processed through an ethyl alcohol dehydration series, the other part was subjected to dehydration and gradual inclusion in HEMA, and a third part of the samples underwent dehydration induced by silica gel and inclusion in procedures 1,2, and 3, respectively, which will be described in detail below.

\section{Procedure 1 - Dehydration in ethyl series}

The first and conventional group, considered the control group, underwent dehydration in ethyl alcohol in concentrations of $10,30,50,70,90$, and $99.5 \%$. The samples were kept in each of the concentrations for $20 \mathrm{~min}$ under continuous rotation. Then, they were embedded in a solution of HEMA and ethyl alcohol (1:1) for $24 \mathrm{~h}$ and pure HEMA for $12 \mathrm{~h}$.

\section{Procedure 2 - Gradual dehydration and infiltration in HEMA}

The second group of samples was placed in aqueous solutions of HEMA and benzoyl peroxide at concentrations of $10,20,30,40,50,60,70,80,90 \%$, and pure resin, with changes of concentration after $50 \mathrm{~min}$. The temperatures were maintained between $20^{\circ} \mathrm{C}$ and $25^{\circ} \mathrm{C}$ and the samples were kept under continuous rotation.

\section{Procedure 3-Induced dehydration and infiltration in HEMA}

The third group of samples was placed in HEMA at concentrations of $10,20,30,40$, and $50 \%$ and was maintained at a variable temperature between $20^{\circ} \mathrm{C}$ and $25^{\circ} \mathrm{C}$ for $24 \mathrm{~h}$ under continuous rotation. Then, the samples were immersed in $1 \mathrm{ml}$ of $50 \%$ HEMA for $48 \mathrm{~h}$ at $20-25^{\circ} \mathrm{C}$ in a microcentrifuge tube modified by removing the central portion of the lids to leave an opening which was then covered with polyester fabric (Fig. 1). This modification enabled the tubes to be closed with the modified lids; however, the closure was not hermetic because of the porosity of the fabric.

Then, the modified microcentrifuge tubes containing resin solution and the samples were vertically inserted into a Becker and completely filled with blue silica gel to indicate humidity. The Becker was then placed in a dehydrating chamber (Fig. 2). It is recommended that a cord be tied to the microcentrifuge tube to facilitate its removal from the Becker (Fig. 2A, C).

\section{Verification of dehydration of the resin in procedures 2 and 3}

After a period of $24 \mathrm{~h}$, a silica gel grain was added to the microcentrifuge tubes in procedures 2 and 3 to verify the degree of dehydration of the HEMA. The silica gel grain was removed after $20 \mathrm{~min}$.

\section{Embedding}

After dehydration and infiltration following the three procedures described, the samples were placed in a $6 \times 9 \mathrm{~mm}$ Histomold Leica. HEMA, which was previously prepared with the activator and the hardening agent derived of barbituric acid, was derived of barbituric acid and was added for polymerization. After $20 \mathrm{~min}$, when polymerization was almost complete, the Histomold was placed in an oven at $50^{\circ} \mathrm{C}$ for $30 \mathrm{~min}$.

\section{Sectioning}

The blocks were sectioned with $3.0 \mu \mathrm{m}$ thickness in a Thermo Scientific Finesse ME+ rotary microtome, utilizing a Thermo Scientific MB34 ${ }^{\circ}$ Dynasharp low-profile disposable blade. The sections were adhered on glass slides with a heating plate at a temperature of $60^{\circ} \mathrm{C}$ for $30 \mathrm{~min}$.

\section{Staining}

Some of the sections of the different samples were stained with $0.05 \%$ Toluidine Blue in a sodium benzoate buffer of $\mathrm{pH} 4.4$ (Feder \& O’Brien 1968). Sudan Black B in 70\% ethanol was used for lipid detection (O’Brien \& McCully 

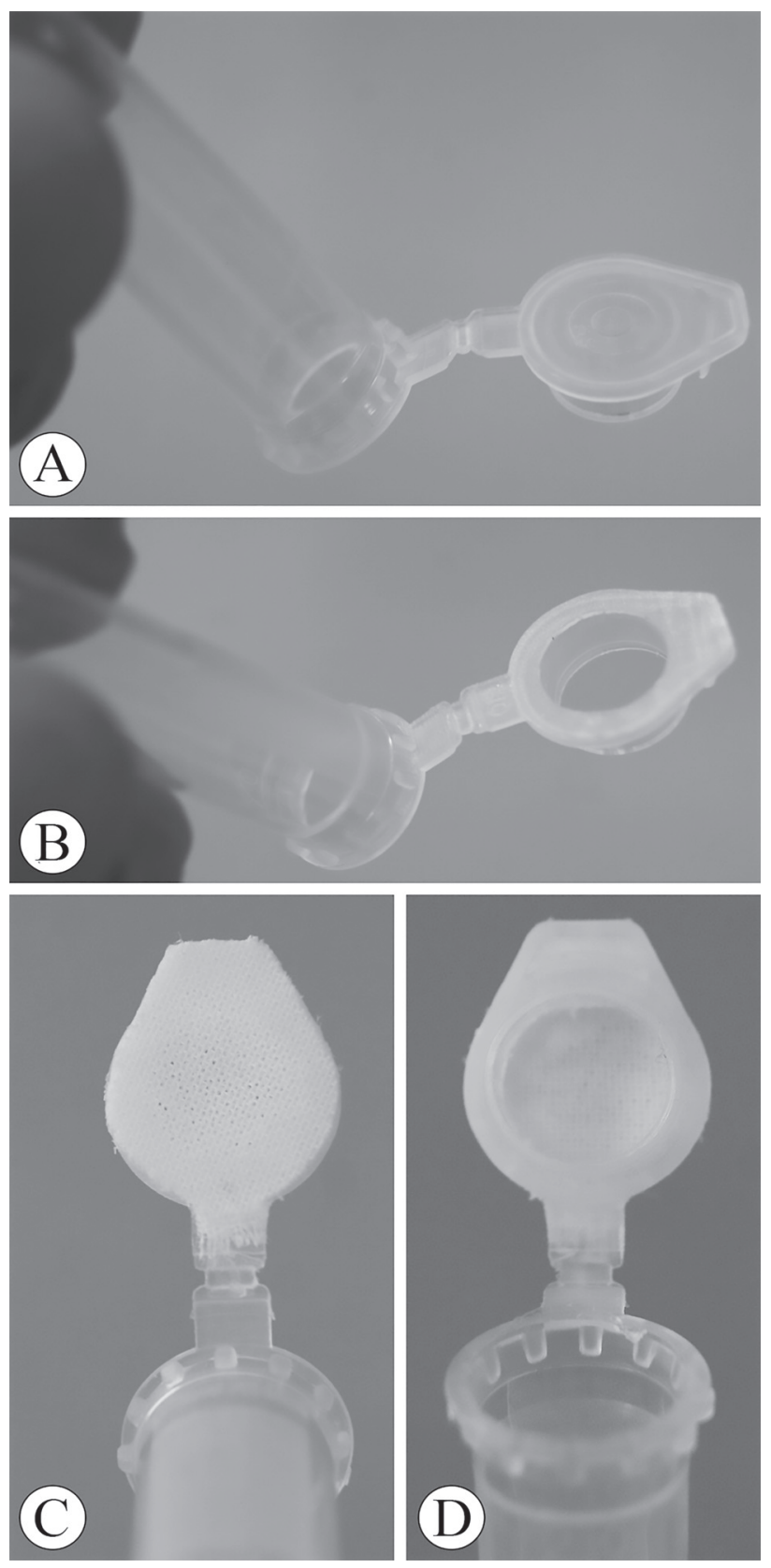

Figure 1. Microcentrifuge tubes: A) Unmodified microcentrifuge tube; B) Central portion of the microcentrifuge tube lid was removed; C) Outside view of the microcentrifuge tube shown in Figure 1B, which was taped on the polyester fabric; D) Inside view of the microcentrifuge tube with polyester fabric adhered.

1981), with time periods of 1,5 , and 30 min for each of the dehydration and infiltration procedures.

\section{Verification of the blue silica gel indicator}

A series of aqueous HEMA solutions with resin concentrations of $10,20,30,40,50,60,70,80,90$, and $95 \%$ were produced, which were identical to those used for both dehydration and infiltration procedures. Verification of the humidity indicator effect of silica gel was conducted after the addition of a grain of silica in the microcentrifuge tube containing HEMA at the different concentrations. Humidity verification by color change of the gel from blue to pink was performed after $1 \mathrm{~min}$ and after $10 \mathrm{~min}$ of addition of the silica grain. Verification of HEMA with activator free of distilled water was also conducted. Color change occurred almost instantly at concentrations up to $50 \%$. The change was slower in solutions of $60 \%$, although the grain was fully changed to the typical pink tone. Color change from blue to pink did not occur at concentrations of $80 \%$ and $90 \%$, with the grains remaining with a bluish tone. No color change occurred after immersion in pure HEMA.

\section{Analysis and photomicrographic documentation}

Analyses and photomicrographic documentation with light microscopy were performed using a Leica DM2000 for the histological slides, with a DFC295 digital camera and Leica Application Suit (LAS) software. The photographic documentation of the microcentrifuge tube and stages of immersion in silica gel were performed using a Sony DSRL a290L digital photographic camera.

\section{Results and Discussion}

Using the conventional procedure, with preceding dehydration in ethyl alcohol followed by infiltration with HEMA, typical results were obtained with excellent sections and verification of adequate infiltration of the tissues as shown in Fig. 3A. However, no lipids were detected with the utilization of Sudan Black B during 5 and 30 min of reaction (Fig. 3B-C) and can be considered to have been removed by the action of ethyl alcohol (Goor et al. 1986). According to Gerrits et al. (1992), the extraction of cellular components through the action of fluids inherent to the processing of the tissues is inevitable. What will be extracted will depend on the hydrophilic/hydrophobic nature and molecular weight of the adopted solvents (Gerrits et al. 1990) and whether the cellular components were weakly fixed or not fixed (Gerrits et al. 1990), as was the case of the lipids in the present procedure.

On comparison of the two dehydration and infiltration procedures performed only in the presence of HEMA, it is notable that gradual dehydration (Fig. 3D-F) closely mimicked the traditional procedure because of the exposure of samples to different resin concentrations and even to pure resin (O’Brien \& McCully 1981; Gabriel 1982; Gerrits et al. 1992). Gradual dehydration without the utilization of ethyl alcohol was initially used in studies aiming to improve infiltration methods for transmission electron microscopy (Stäubli 1963; Leduc \& Bernhard 1967; Newman \& Hobot 1999), in studies investigating the location of enzymes in animal and plant tissues (Rosenberg et al. 1960; Leduc \& Bernhard 1967; Ashford et al. 1972; Newman \& Hobot 1999), or for lipid preservation in animal tissues (Goor et al. 1986; Meyer et al. 2009). 

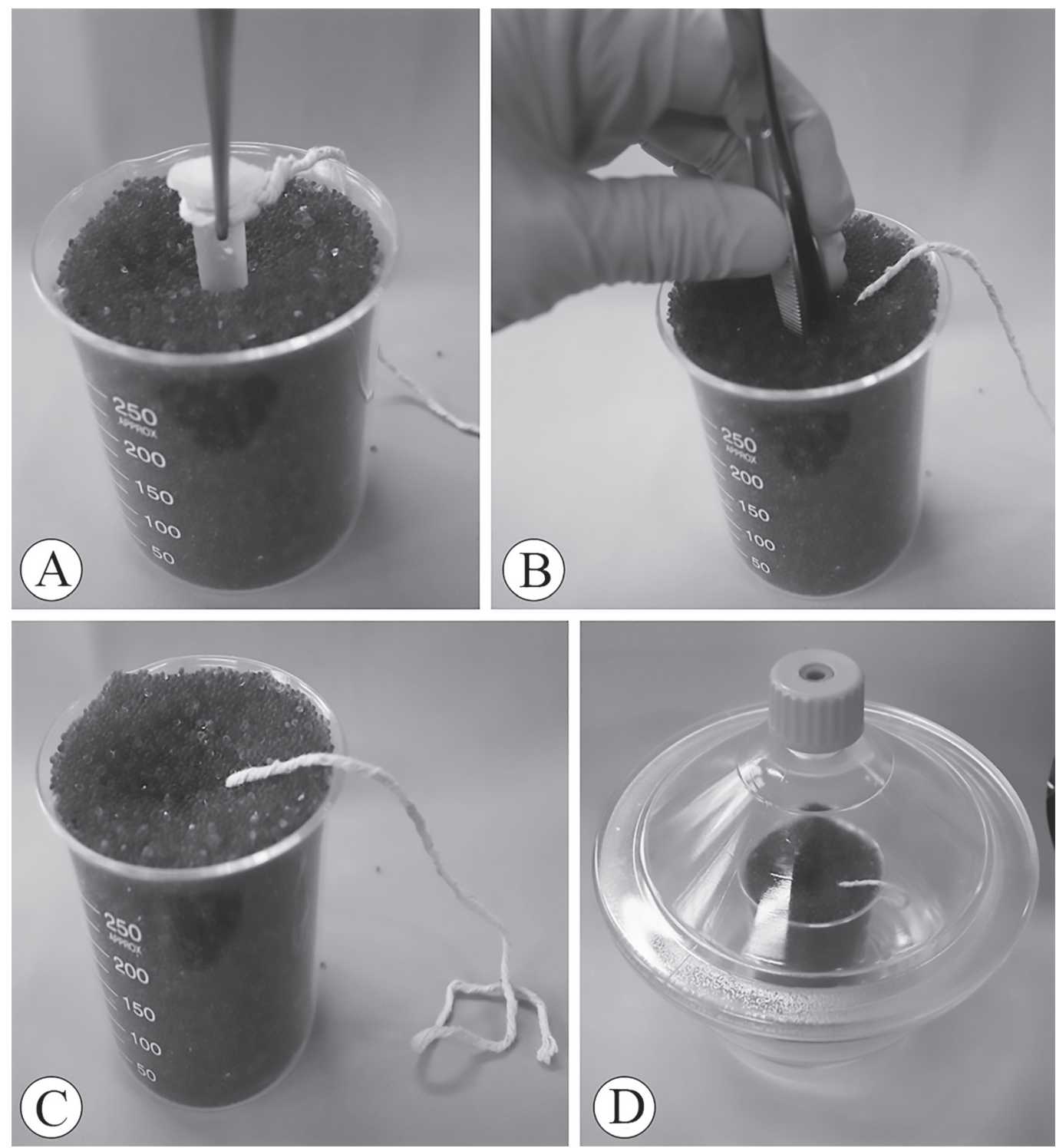

Figure 2. Steps of the immersion and isolation of the microcentrifuge tube into the Becker with silica gel: A) Correct orientation of the microcentrifuge tube in the flask. Note the cord tied to the tube; B) Immersion of the microcentrifuge tube with tweezers. It is recommended that the bottom of the microcentrifuge tube reaches the bottom of the Becker; C) Detail of the cord to guide the removal of the microcentrifuge tube; D) The flask contains silica gel and it is placed in a desiccator.

Gradual dehydration and infiltration provided satisfactory infiltration in large portions of the tissues; however, there was insufficient infiltration in some regions (Fig. 3D). Tests with Sudan Black B showed that the lipids were maintained in single cells or groups of cells in the first $5 \mathrm{~min}$ of reaction (Fig. 3E). The increase in reaction time to $30 \mathrm{~min}$ did not bring about any increase in the indication of lipids in the tissues (Fig. 3F).

The third procedure used the water adsorption property of silica gel to induce dehydration. Thus, a microenvironment, which is suitable to dehydration, was created inside the microcentrifuge tube. It was estimated that a large volume of silica gel involving the tube would maintain the dry air in the microenvironment of the modified microcentrifuge tube; therefore, water would be continuously removed from the solution. On losing equilibrium of the quantity of water in the solution, water from the tissues would pass to the solution and progressively to the microcentrifuge tube environment, thus resulting in adsorption by the external silica gel. Dehydration and infiltration of cells and tissues would occur simultaneously. Thus, after 2 days of incubation at room temperature $\left(20-25^{\circ} \mathrm{C}\right)$, dehydration of the solution was observed from its reduction to half of its volume and also from the maintenance of a bluish color of the grain of silica gel added to the solution.

Immediately after observing these conditions of the solution, comparisons were made between the color of the grain of silica gel immersed with the plant tissue and the resulting coloration of the grain of silica gel after addition to reference solutions. Based on the observation that the color 
of the silica grain was very close to that of grains immersed in pure HEMA, the tissues were considered to be adequately dehydrated and apt for embedding.

Infiltration problems in some of the portions of the endosperm were detected after sectioning (Fig. 3G). During the gradual dehydration of roots of Zea mays, when changes of different concentration of solutions of glycol methacrylate were made, a period of 2 weeks was allowed for the organ to remain in the reagent, with satisfactory infiltration (Ashford et al. 1972). In the present study, it is notable that a greater period of immersion in resin at temperatures between $20^{\circ} \mathrm{C}$ and $25^{\circ} \mathrm{C}$ for dehydration and adequate infiltration can also lead to lipid losses (Hayat 1970), an aspect which should be considered in future studies. In this context, Gerrits et al. (1992) reported the possibility of large lipid losses with the use of HEMA as a dehydrating agent. According to Cope \& Williams $(1968 ; 1969)$, the extraction of lipids by HEMA is because of its hydrophobicity, which is even greater than that of ethyl alcohol.

In the present study, the total time of immersion of the dehydrated samples in ethyl alcohol in the control group was $2 \mathrm{~h}$, whereas the immersion time in HEMA was approximately $7 \mathrm{~h}$ for gradual dehydration and 7 days for dehydration and infiltration being 5 days by a gradual process followed by 2 days induced by silica gel. Although the potential of methacrylate resins, including HEMA, to extract lipids has been reported, a greater lipid preservation was observed in both procedures of dehydration and infiltration with resin than with ethanol.

A relevant result found in the simultaneous dehydration and infiltration induced by silica gel was that the detection of lipid deposits occurred after 1 min of reaction with Sudan Black B (Fig. 3H) and intensified after 5 min (Fig. 3I). No further difference in the intensity of the reaction or quantity
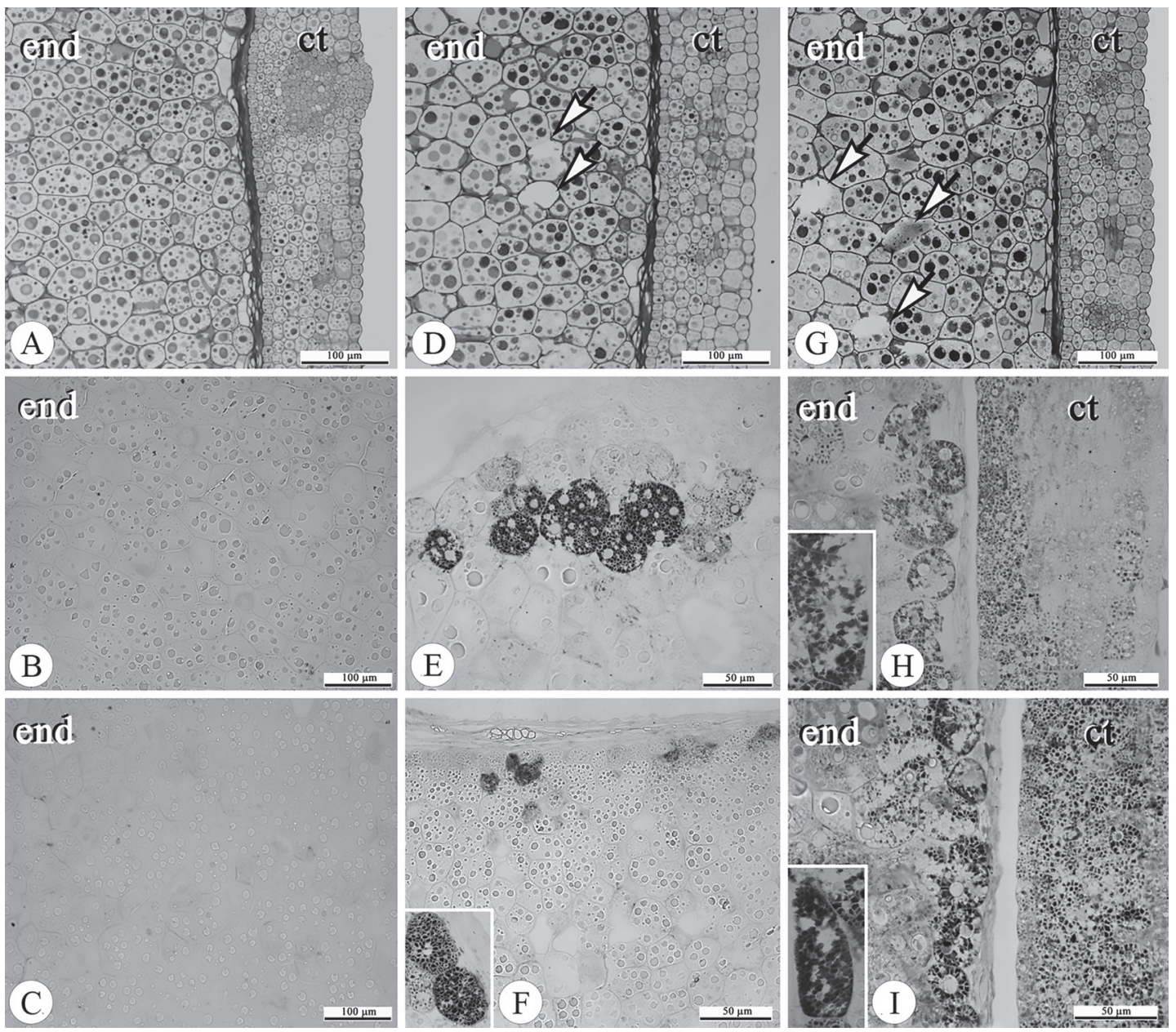

Figure 3. Cross sections of Ricinus communis seeds, including endosperm and cotyledon, under light microscopy: A-C) Dehydration in an ethanol series: A) Staining with toluidine blue O; B) Sudan Black B after 5 min; C) Sudan Black B after 30 min. D-F) Dehydration and gradual infiltration in ascending series of HEMA: D) Endosperm and cotyledon after staining with toluidine blue O. Poor infiltration and embedding indicated by arrows; E) Sudan Black B after 5 min. Some cells had cytoplasm containing large amounts of lipid droplets; F) Sudan Black B after 30 min. Detail of the endosperm show cells with lipid droplets occupying the entire cell volume. E and F shows the endosperm only. G-I) Dehydration induced by silica gel and infiltration: G) Staining with toluidine blue O. Poor infiltration and embedding of the endosperm indicated by arrows; H) Sudan Black B after 1 min. Detail shows epidermal cell of the cotyledon with lipid droplets occupying much of its volume; I) Sudan Black B after 5 min. Detail shows the endosperm cell filled with lipid droplets.

end $=$ endosperm, $\mathbf{c t}=$ cotyledon . 
of cells with lipids was observed after $30 \mathrm{~min}$ of reaction. In addition, lipid preservation in the tissues was superior in relation to the dehydration in ethyl alcohol, i.e., virtually all of the cells included in the endosperm and embryo presented lipids (Fig. 3H-I). According to O’Brien \& McCully (1981), the indication of lipids with Sudan Black B occurs between 30 $\mathrm{s}$ and $1 \mathrm{~min}$ in fresh tissues sectioned by hand and in $6 \mathrm{~h}$ for tissues dehydrated in ethyl alcohol and infiltrated in HEMA. Simultaneous dehydration and infiltration induced by silica gel resulted in lipid detection in a period similar to that described for fresh material and allowed for the preservation of lipids in a large number of cells as well as tissue sectioning with a microtome. Goor et al. (1986) proposed a simple and successful procedure for lipid preservation in different human tissues including tumors. The authors performed the fixation of tissues in a solution of $4 \%$ formaldehyde in phosphate buffer, washed the tissues in the same buffer, and then immersed the tissues in pure glycol methacrylate (Technovit $\left.7100^{\mathrm{m}}\right)$. The total period of tissues dehydration in resin was $2 \mathrm{~h}$ (Goor et al. 1986). The sectioned tissues were compared to similar material submitted to cryomicrotomy with identical results for lipid localization using Sudan Black B and Oil Red O (Goor et al. 1986). One of the objectives of Goor et al. (1986) was related to the optimization of routine histopathological biopsies, and it is notable that besides achieving lipid preservation, the dehydration-infiltration period was short and pure resin was also used.

In conclusion, the three procedures allowed the dehydration and infiltration of plant material, although infiltration was less effective with the use of only HEMA as a dehydrating agent. Simultaneous dehydration and infiltration gave excellent results in terms of lipid preservation. The use of resin as the only dehydrating agent eliminates artifacts of ethyl alcohol on cells and tissues, i.e., mainly the removal of lipids. In addition, material resources or techniques besides those generally available in histological laboratories are not necessary. Thus, the use of simultaneous dehydration and infiltration as proposed in this study are recommended as a complementary procedure once the lipid preservation is desired in the cells and tissues studied.

\section{Acknowledgements}

The author thanks the graduate student Jordano Dorval Tavares de Carvalho for his collaboration in plant microtechniques.

\section{References}

Ashford AE, Allaway WG, McCully ME. 1972. Low temperature embedding in glycol methacrylate for enzyme histochemistry in plant and animal tissues. Journal of Histochemistry \& Cytochemistry 20: 986-990.

Baker JR. 1958. Principles of Biological Microtechnique. A Study of Fixation and Dyeing. New York, John Wiley \& Sons, Inc.

Bozzola JJ, Russell LD. 1999. Electron Microscopy. Principles and Techniques for Biologists. Massachusetts, Jones \& Bartlett Learning.

Cope GH, Williams MA. 1968. Quantitative studies on neutral lipid preservation in electron microscopy. Journal of the Royal Microscopical Society 88: 259-277.

Cope GH, Williams MA. 1969. Quantitative studies on the preservation of choline and ethanolamine phosphatides during tissue preparation for electron microscopy. Journal of Microscopy 90: 31-46.

Dashek WV. 2000. Methods in Plant Electron Microscopy and Cytochemistry. New Jersey, Humana Press Inc.

Feder N, O'Brien TP. 1968. Plant microtechnique. Some principles and new methods. American Journal of Botany 55: 123-142.

Fritz E, Eschrich W. 1970. ${ }^{14} \mathrm{C}$-Mikroautoradiographie wasserlöslicher substanzen im phloem. Planta 92: 267-281.

Gabriel BL. 1982. Biological Electron Microscopy. New York, Van Nostrand Reinhold Company.

Gerrits PO, Horobin RW, Hardonk MJ. 1990. A numerical procedure for choosing effective, low toxicity plasticizers for glycol methacrylate embedding. The Histochemical Journal 22: 439-451.

Gerrits PO, Horobin RW, Stokroos I. 1992. The effects of glycol methacrylate as a dehydrating agent on the dimensional changes of liver tissue. Journal of Microscopy 165: 273-280.

Goor H, Gerrits PO, Grond J. 1986. The application of lipid-soluble stains in plastic-embedded sections. Histochemistry 85: 251-253.

Hayat MA. 1970. Principles and Techniques of Electron Microscopy. Biological applications. New York, Van Nostrand Reinhold Company.

Jensen WA. 1962. Botanical Histochemistry. San Francisco and London, W. H. Freeman \& Co.

Korn ED, Weisman RA. 1966. I. Loss of lipids during preparation of amoebae for electron microscopy. Biochimica et Biophysica Acta 116: 309-316.

Läuchli A, Spurr AR, Wittkopp RW. 1970. Electron probe analysis of freezesubstituted, epoxy resin embedded tissue for ion transport studies in plants. Planta 95: 341-350.

Leduc EH, Bernhard W. 1967. Recent modifications of the glycol methacrylate embedding procedure. Journal of Ultrastructure Research 19: 196-199.

Meyer W, Schmidt J, Busche R, Jacob R, Naim HY. 2009. Demonstration of lipids in plastic resin-embedded sections of skin material. Journal of Microscopy 233: 5-9.

Newman GR, Hobot JA. 1999. Resins for combined light and electron microscopy: a half century of development. The Histochemical Journal 31: 495-505.

O'Brien TP, McCully ME. 1981. The Study of Plant Structure Principles and Selected Methods. Melbourne, Termarcarphi Pty Ltd.

Reed BM. 2008. Plant Cryopreservation: A practical guide. New York, Springer.

Rosenberg M, Bartl P, Lesko J. 1960. Water-soluble methacrylate as an embedding medium for the preparation of ultrathin Sections. Journal of Ultrastructure Research 4: 298-303.

Stäubli W. 1963. A new embedding technique for electron microscopy, combining a water-soluble epoxy resin (Durcupan) with water insoluble Araldite. Journal of Cell Biology 16: 197-201. 